\title{
Identification and molecular epidemiology of methicillin resistant Staphylococcus pseudintermedius strains isolated from canine clinical samples in Argentina
}

Paula Gagetti ${ }^{1,5}$, Alice R. Wattam² ${ }^{2}$ Gabriela Giacoboni ${ }^{3}$, Adriana De Paulis ${ }^{4}$, Eugenia Bertona ${ }^{4}$, Alejandra Corso ${ }^{1}$ and Adriana E. Rosato ${ }^{5^{*}}$ (D)

\begin{abstract}
Background: Staphylococcus pseudintermedius is the leading cause of pyoderma in dogs and the frequent use of antimicrobial treatment is associated to the development of resistance to nearly all classes of antibiotics. Despite $S$. pseudintermedius significance, our understanding of the molecular mechanism of $\beta$-lactam resistance and its genetic diversity remains limited. We aimed to: i) determine the phenotypic resistance profile of methicillin resistant Staphylococcus pseudintermedius (MRSP) isolated from infected dogs in three different veterinary hospitals in Buenos Aires, Argentina; ii) identify the SCCmec elements and resistance genes; and iii) analyze the clonal relationship between isolates and in regard of dominant lineages found in the world.

Results: In addition to the differential levels of $\beta$-lactam resistance, MRSP isolates $(n=10)$ showed resistance to $5-6$ families of antibiotics, and were therefore categorized as multidrug-resistant. All the isolates were variant of SCCmec $\checkmark$ homologous to S. aureus; additional SCCmecFinder analysis classified five of the genomes as SCCmec type $V$ (5C2\&5) with mecA (encodes for PBP2a), mecRl and mecl and all the genes closely related to the reference SCCmec type $V$ S. aureus TSGH17 strain. In the remaining five strains, mecA was present, although other genes associated with SCCmec V including mecR1 and mecl were missing. PBP2a was inducible in low level resistance strains (MRSP 8151), and constitutively expressed in MRSP 8150, suggesting different mecA regulatory mechanisms. MRSP isolates showed significant genetic diversity: eight PFGE clonal types and six multilocus-sequence typing (MLST) sequence types (STs) (339, 649, 919, 920, 921 and 922), including four new STs genetically distinct from STs reported in other geographic areas. Comparative genomics and phylogenetic analyses of the MRSP showed a correlation between the genetic content and the phenotypes, and established the genetic relationship between the isolates.

Conclusions: MRSP could be a threat to animal health due to it concerning level of antimicrobial resistance. Our study highlights genetic and epidemiological aspects of multidrug-resistant MRSP strains from Argentina showing high degree of correlation between the resistance genes and the phenotype of the isolates and, furthermore, they appeared evolutionary closer to major worldwide reported ST68 and ST71.
\end{abstract}

Keywords: MRSP, Antibiotic resistance, Zoonosis, Small animals

\footnotetext{
* Correspondence: aerosato@houstonmethodist.org

${ }^{5}$ Department of Pathology and Genomic Medicine, Houston Methodist

Research Institute, Houston, TX, USA

Full list of author information is available at the end of the article
}

(c) The Author(s). 2019 Open Access This article is distributed under the terms of the Creative Commons Attribution 4.0 International License (http://creativecommons.org/licenses/by/4.0/), which permits unrestricted use, distribution, and reproduction in any medium, provided you give appropriate credit to the original author(s) and the source, provide a link to the Creative Commons license, and indicate if changes were made. The Creative Commons Public Domain Dedication waiver (http://creativecommons.org/publicdomain/zero/1.0/) applies to the data made available in this article, unless otherwise stated. 


\section{Background}

S. pseudintermedius is an important pathogen in dogs and cats and is sporadically associated with human infections [1]. Over the past decade, methicillin resistant $S$. pseudintermedius (MRSP) has emerged in different parts of the world and has become one of the most important bacterial pathogens in small-animal-veterinarymedicine [2, 3]. Based on data from the World Health Organization (WHO) and the United Nations in 2016, antimicrobial resistance in humans, like in companion animals, represents a problem for public health.

The $\beta$-lactam resistance of MRSP is due to penicillinbinding protein $2 \mathrm{a}(\mathrm{PBP} 2 \mathrm{a})$, a protein encoded by the methicillin resistant gene $\operatorname{mec} A$. This gene is known to reside in a mobile genetic element, a staphylococcal cassette chromosome designated SCCmec that contains the mec gene complex, mecA and some additional genes, and the cassette chromosome recombinase ( $c c r$ ) gene complex, which is responsible for insertion of the SCCmec cassette into the core genome. So far as many as thirteen different structural types of SCCmec have been described in $S$. aureus based on the different combinations of class of mec complexes according to the presence/absence of regulatory genes and insertion sequences, and $c c r$ allotypes $(c c r A B$ and $c c r C)$ [4]. Eleven main types, subtypes, and variants have already been described in the database of the International Working Group on the Staphylococcal Cassette Chromosome (IWG-SCC) [5]. Some S. aureus and coagulase-negative Staphylococcus isolates carry a mecA homolog, mecC, which has been recently reported carried by SCCmec XI $[6,7]$. The classification of SCCmec elements is complex, given that there are composite cassettes and pseudo-SCCmec elements that do not harbor ccr genes [8]. While in S. aureus the structure of SCCmec elements has been shown to be relatively stable, in MRSP the SCCmec elements showed high genetic diversity [4].
The cefoxitin disk is considered as the main method for methicillin resistance detection in S. aureus, nevertheless this is not an accurate method of screening for methicillin resistance in $S$. pseudintermedius $[9,10]$, that must be detected with the oxacillin disk.

In Argentina, previous studies have revealed a prevalence of methicillin resistance between 10 and $30 \%$ of S. pseudintermedius clinical isolates obtained from dogs $[11,12]$.

Several dominant MRSP lineages have been identified in the world, including ST45, ST68 and ST71 [8], but the molecular epidemiology of MRSP clones circulating in Argentina has not been examined.

The aims of this study were to determine the phenotypic resistance profile of MRSP, to identify the SCCmec elements and resistance genes, to analyze the clonal relationship between isolates, and to compare these isolates with the dominant lineages found globally.

\section{Results}

\section{Antibiotic resistance profiles}

All the $S$. pseudintermedius isolates were considered resistant to oxacillin based on the recently revised Clinical and Laboratory Standards Institute (CLSI) breakpoints of $S$. pseudintermedius, the presence of mecA gene and a SCCmec element. We identified from the total of 10 MRSP strains two distinct groups with different expression of $\beta$-lactam resistance. Six of the ten isolates displayed low-level of oxacillin resistance with minimal inhibitory concentration (MIC) values in the range of 0.5 to $2 \mathrm{mg} / \mathrm{L}$ despite being $\operatorname{mec} A$ positive, and the rest (4 of 10 isolates) exhibited high-level resistant $(\geq 8 \mathrm{mg} / \mathrm{L})$ (Table 1). All the strains were resistant to oxacillin, penicillin, streptomycin and kanamycin. In addition to the $\beta$-lactam resistance gene $m e c A$, all the isolates contained the $\beta$-lactamase gene blaZ, the kanamycin and neomycin phosphotransferase gene aph (3')-III and the streptomycin adenylyl-nucleotidyltransferase gene ant(6)-Ia. Resistance to macrolides, lincosamides, and

Table 1 Phenotypic and genotypic characteristics of the MRSP strains

\begin{tabular}{|c|c|c|c|c|c|c|c|c|c|c|c|c|c|c|c|c|c|c|c|c|c|c|c|c|c|}
\hline \multirow{3}{*}{ Isolate ID } & \multirow{3}{*}{$\begin{array}{c}\text { Year of } \\
\text { isolation }\end{array}$} & \multirow{3}{*}{ Source } & \multicolumn{4}{|c|}{ OXA } & \multirow{3}{*}{\multicolumn{2}{|c|}{$\begin{array}{c}\text { FOX } \\
\text { Zone } \\
(\mathrm{mm})\end{array}$}} & \multicolumn{13}{|c|}{ Susceptibility profile } & \multirow{3}{*}{$\begin{array}{c}\text { PCR } \\
m e c \mathrm{~A}\end{array}$} & \multirow{3}{*}{$\begin{array}{c}\text { SCCmec } \\
\text { type }\end{array}$} & \multirow{3}{*}{$\begin{array}{l}\text { Sma I } \\
\text { PFGE }\end{array}$} & \multirow{3}{*}{ MLST } \\
\hline & & & \multicolumn{2}{|c|}{ MIC (mg/L) } & \multirow{2}{*}{\multicolumn{2}{|c|}{$\begin{array}{r}\text { Zone } \\
\text { (mm) }\end{array}$}} & & & \multirow{2}{*}{\multicolumn{2}{|c|}{ PEN ERY }} & \multirow[b]{2}{*}{ CLI } & \multirow[b]{2}{*}{ TET } & \multirow[b]{2}{*}{ CMP } & \multirow[b]{2}{*}{ RFA } & \multirow[b]{2}{*}{ GEN } & \multirow[b]{2}{*}{ STR } & \multirow[b]{2}{*}{ KAN } & \multirow[b]{2}{*}{ SXT } & \multirow[b]{2}{*}{ NIT } & \multirow{2}{*}{\multicolumn{2}{|c|}{ LNZ CIP }} & & & & \\
\hline & & & E-test & $\begin{array}{c}\text { Agar } \\
\text { Dilution }\end{array}$ & & & & & & & & & & & & & & & & & & & & & \\
\hline MRSP 8148 & 2008 & pyoderma & $>256$ & $>8$ & 6 & $\mathbf{R}$ & 30 & $\mathrm{~S}$ & $\mathbf{R}$ & $\mathbf{R}$ & $\mathbf{R}$ & $\mathrm{S}$ & $S$ & $\mathrm{~S}$ & $\mathrm{~S}$ & $\mathbf{R}$ & $\mathbf{R}$ & $\mathrm{S}$ & $\mathrm{S}$ & $\mathrm{S}$ & $\mathbf{R}$ & pos & V like & $\mathrm{C}$ & ST919 \\
\hline MRSP 8150 & 2009 & pyoderma & $>256$ & $>8$ & 6 & $\mathbf{R}$ & 25 & $S$ & $\mathbf{R}$ & $\mathbf{R}$ & $\mathbf{R}$ & S & S & S & $\mathrm{S}$ & $\mathbf{R}$ & $\mathbf{R}$ & $\mathbf{R}$ & $\mathrm{S}$ & S & $\mathbf{R}$ & pos & V like & $\mathrm{D}$ & ST339 \\
\hline MRSP 8151 & 2010 & ear & 2 & 1 & 10 & $\mathbf{R}$ & 32 & $\mathrm{~S}$ & $\mathbf{R}$ & $\mathbf{R}$ & $\mathbf{R}$ & $\mathrm{S}$ & S & $\mathrm{S}$ & $\mathbf{R}$ & $\mathbf{R}$ & $\mathbf{R}$ & $\mathbf{R}$ & $\mathrm{S}$ & $\mathrm{S}$ & $\mathbf{R}$ & pos & V like & $\mathrm{E}$ & ST 920 \\
\hline MRSP 8468 & 2011 & unknown & 0.75 & 0.5 & 16 & $\mathbf{R}$ & 33 & $S$ & $\mathbf{R}$ & $\mathrm{S}$ & $\mathrm{S}$ & $\mathbf{R}$ & S & $\mathrm{S}$ & $\mathrm{S}$ & $\mathbf{R}$ & $\mathbf{R}$ & $\mathbf{R}$ & $\mathrm{S}$ & $S$ & $S$ & pos & V like & A & ST649 \\
\hline MRSP 8469 & 2011 & unknown & 0.5 & 0.5 & 16 & $\mathbf{R}$ & 34 & S & $\mathbf{R}$ & $\mathrm{S}$ & $\mathrm{S}$ & $\mathbf{R}$ & S & $\mathrm{S}$ & $\mathrm{S}$ & $\mathbf{R}$ & $\mathbf{R}$ & $\mathbf{R}$ & $\mathrm{S}$ & S & S & pos & V like & A & ST649 \\
\hline MRSP 8470 & 2011 & unknown & 8 & 8 & 12 & $\mathbf{R}$ & 26 & $\mathrm{~S}$ & $\mathbf{R}$ & $\mathbf{R}$ & $\mathbf{R}$ & $\mathrm{S}$ & S & $\mathrm{S}$ & $\mathrm{S}$ & $\mathbf{R}$ & $\mathbf{R}$ & $\mathbf{R}$ & $\mathrm{S}$ & $\mathrm{S}$ & $\mathbf{R}$ & pos & V like & B & ST919 \\
\hline MRSP 8471 & 2011 & unknown & 16 & 8 & 12 & $\mathbf{R}$ & 22 & $S$ & $\mathbf{R}$ & $\mathbf{R}$ & $\mathbf{R}$ & $\mathrm{S}$ & S & $\mathrm{S}$ & $\mathrm{S}$ & $\mathbf{R}$ & $\mathbf{R}$ & $\mathbf{R}$ & $\mathrm{S}$ & S & $\mathbf{R}$ & pos & V like & B & ST919 \\
\hline MRSP 8472 & 2011 & wound & 1 & 2 & 10 & $\mathbf{R}$ & 30 & $S$ & $\mathbf{R}$ & $\mathbf{R}$ & $\mathbf{R}$ & $\mathrm{S}$ & S & $\mathrm{S}$ & $\mathrm{S}$ & $\mathbf{R}$ & $\mathbf{R}$ & $\mathbf{R}$ & $\mathrm{S}$ & $\mathrm{S}$ & $\mathbf{R}$ & pos & V like & $\mathrm{F}$ & ST339 \\
\hline MRSP 8473 & 2011 & vagina & 1.5 & 2 & 6 & $\mathbf{R}$ & 28 & $S$ & $\mathbf{R}$ & $\mathbf{R}$ & $\mathbf{R}$ & $\mathbf{R}$ & S & $\mathrm{S}$ & $\mathrm{S}$ & $\mathbf{R}$ & $\mathbf{R}$ & $\mathbf{R}$ & $\mathrm{S}$ & $\mathrm{S}$ & $\mathrm{S}$ & pos & V like & G & ST921 \\
\hline MRSP 8474 & 2011 & ear & 1.5 & 2 & 6 & $\mathbf{R}$ & 26 & $\mathrm{~S}$ & $\mathbf{R}$ & $\mathbf{R}$ & $\mathbf{R}$ & $\mathrm{S}$ & $\mathrm{S}$ & $\mathrm{S}$ & $\mathrm{S}$ & $\mathbf{R}$ & $\mathbf{R}$ & $\mathbf{R}$ & $\mathrm{S}$ & $\mathrm{S}$ & $\mathbf{R}$ & pos & V like & $\mathrm{H}$ & ST922 \\
\hline
\end{tabular}

OXA oxacillin, FOX cefoxitin, PEN penicillin, ERY erythromycin, CLI clindamycin, TET tetracycline, CMP chloramphenicol, RFA rifampicin, GEN gentamicin, STR streptomycin, KAN kanamycin, SXT trimethoprim-sulfamethoxazole, NIT nitrofurantoin, LNZ linezolid and CIP ciprofloxacin, $S$ susceptible, $R$ resistant. 
streptogramins-B seen in eight isolates was due to the methylase gene ermB, and all of them displayed constitutive resistance to clindamycin. The nine trimethoprim/ sulfamethoxazole-resistant isolates contained the dihydrofolate reductase gene $d f r G$, and the three tetracycline resistant isolates carried the tetracycline and minocycline resistance gene tet $M$. Only one strain was resistant to gentamicin, and it had the $a a c\left(6^{\prime}\right)-I e-a p h\left(2^{\prime}\right)-I a$ gene. Table 2 summarizes the genes associated with resistance and the antimicrobial resistance phenotype displayed by the isolates.

In addition, mutations in the quinolone resistancedetermining region (QRDR) of the topoisomerase genes of the seven ciprofloxacin-resistant isolates were found, including amino acid substitution S84 L in the topoisomerase GyrA and S80I in GrlA. Additional amino acid substitutions were identified outside the QRDR of the topoisomerase genes (Table 3), but their role in fluoroquinolone resistance was not determined. The isolate MRSP 8472 has only one amino acid substitution in grlA gene and remained susceptible to ciprofloxacin. No mutations were found in the $\operatorname{gyr} B$ and $\operatorname{grlB}$ genes in any of the isolates. All the isolates were susceptible to chloramphenicol, rifampicin, nitrofurantoin and linezolid. All the MRSP strains in the present study were resistant to more than three antimicrobial classes and therefore were classified as multidrug-resistant (MDR) [13].

\section{Differential levels of PBP2a expression in MRSP correlates with their $\beta$-lactam resistance}

Resistance to methicillin in S. pseudintermedius, as well as in $S$. aureus is due to the presence of the mecA gene, which encodes penicillin-binding protein 2a (PBP2a); this protein shows reduced affinity for all $\beta$-lactam antimicrobials. S. aureus strains that have the mecA gene incorporated in the genetic element SCCmec are considered to be resistant to all $\beta$-lactam antimicrobials. Analysis of PBP2a by Western blot was performed by using specific anti-PBP2a antibodies in protein lysates of MRSP strains expressing either high level of oxacillin resistance (MRSP 8150, oxacillin MIC $>256 \mathrm{mg} / \mathrm{L}$ ) or low (MRSP 8151, oxacillin MIC $2 \mathrm{mg} / \mathrm{L}$ ) grown without and with sub-inhibitory concentrations of oxacillin and cephalexin at $0.5 \mu \mathrm{g} / \mathrm{ml}$. As shown in Fig. 1, while PBP2a was inducible in strains expressing low levels of resistance (i.e MRSP 8151), it appeared to be constitutively expressed in MRSP 8150, suggesting different regulatory mechanisms in MRSP. Furthermore, the strain MRSP 8150 has both blaI/blaR1 and mecI/mecR1 genes unlike MRSP 8151 that only has blaI/blaR1. These results may indicate that $\beta$-lactam expression in MRSP strains could be linked to $m e c A$ differential regulation.

\section{Characterization of the SCCmec element in MRSP strains}

Characterization of the SCCmec cassette was performed by multiplex PCR showing that all the isolates displayed the same pattern of bands, but different from the control isolates SCCmec I to VI. The pattern shared two bands with the SCCmec type $\mathrm{V}$ element corresponding to mecA and $c c r$ complex, but differed in the band corresponding to $\mathrm{J} 1$ region suggesting that it could be a variant of SCCmec V (Fig. 2).

Each of the strain genomes was submitted to SCCmecFinder [14], an in silico web-based bioinformatic tool that identifies and types SCCmec elements. Using this, the SCCmec type V (5C2 and 5) / SCCmec type $\mathrm{Vb}$ (5C2 and 5) was identified in five of the genomes, indicating that there was significant homology with $S$. aureus AB512767.1 (TSGH17), which was used as a reference. Further BLAST analysis between all the genes annotated in AB512767.1 showed that all the SCCmec V genes found in the cassette were present on a single contig in MRSP 8472, while the other isolates that had the genes on more than one contig. The fastq files from nine isolates were mapped against the MRSP 8472 genome to see if any reads mapped to these genes, or to other genes known to be present in the SSCmec cassette. This comparison showed that five of the genomes (MRSP isolates 8150, 8468, 8469, 8472 and 8473) have mecA, mecR1 and $m e c I$, and the majority of the genes that are present in AB512767.1 (Fig. 3). Two of these genomes (MRSP isolates 8150 and 8472 ) had all of the genes present in AB512767.1 and three of them (MRSP 8468, 8469 and 8473) have mecA, mecR1 and mecI, but were missing the last two genes on the $5^{\prime}$ end. The remaining five genomes (MRSP 8148, 8151, 8470, 8471 and 8474) have

Table 2 Resistance Genes and Antimicrobial Resistance Phenotypes of the MRSP strains

\begin{tabular}{|c|c|c|}
\hline No. of Isolates & Resistance Genes & Antimicrobial Resistance Phenotype \\
\hline 5 & mecA, blaZ, ermB, dfrG, aph(3')-III, ant(6)-la & OXA, PEN, ERY, CLI, STR, KAN, SXT, CIP* \\
\hline 2 & mecA, blaZ, tetM, dfrG, aph(3')-III, ant(6)-la & OXA, PEN, TET, STR, KAN, SXT \\
\hline 1 & 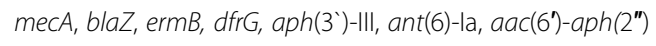 & OXA, PEN, ERY, CLI, GEN, STR, KAN, SXT, CIP* \\
\hline 1 & mecA, blaZ, ermB, tetM, dfrG, aph(3')-III, ant(6)-la & OXA, PEN, ERY, CLI, TET, STR, KAN, SXT \\
\hline 1 & mecA, blaZ, ermB, aph(3')-III, ant(6)-la & OXA, PEN, ERY, CLI, STR, KAN, CIP* \\
\hline
\end{tabular}

* The amino acid substitutions related to the CIP resistance are shown in Table 3 
Table 3 Amino acid substitutions in the topoisomerase genes of the 10 MRSP strains

\begin{tabular}{|c|c|c|c|c|c|c|c|c|}
\hline \multirow{3}{*}{$\frac{\text { Nro }}{\text { MRSP } 8148}$} & \multicolumn{5}{|c|}{ gyrA } & \multicolumn{3}{|c|}{ grlA } \\
\hline & \multicolumn{5}{|c|}{ P5S S84L D447E H557Q K736N } & \multicolumn{3}{|c|}{ S80I I516T Q611L } \\
\hline & + & + & + & + & + & + & + & - \\
\hline MRSP 8150 & + & + & + & + & + & + & + & - \\
\hline MRSP 8151 & + & + & + & + & + & + & + & - \\
\hline MRSP 8468 & - & - & - & - & - & - & - & - \\
\hline MRSP 8469 & - & - & - & - & - & - & - & - \\
\hline MRSP 8470 & + & + & + & + & + & + & + & - \\
\hline MRSP 8471 & + & + & + & + & + & + & + & - \\
\hline MRSP 8472 & + & + & - & - & - & + & + & + \\
\hline MRSP 8473 & - & - & - & - & - & + & + & - \\
\hline MRSP 8474 & - & + & + & + & + & + & + & - \\
\hline
\end{tabular}

$m e c A$, but were missing many of the other genes associated with SCCmec V, including mecR1 and mecI (Fig. 3). These results suggest that MRSP strains harboring $m e c A$ are differentiated into two distinct groups.

\section{Population structure analysis}

To identify the relatedness of the MRSP strains PFGE was performed. We found that the ten MRSP strains were differentiated in eight clonal types (A to $\mathrm{H}$ ). Moreover, identical patterns were observed between MRSP 8468 and MRSP 8469 strains (type A) while MRSP 8470 and MRSP 8471 strains displayed type B (Additional file 1: Figure S1). Additionally, MRSP type characterization was performed by using MLST as described in Methods. We found that the MRSP strains were differentiated into six different STs.

Two of them MRSP 8150 and MRSP 8472 belong to ST339 while MRSP 8468 and MRSP 8469 were related to ST649. These ST types have been described and already included in PubMLST database. The six remaining isolates had previously undescribed allelic profiles and were assigned new sequence types by the $S$. pseudintermedius MLST database curator. MRSP 8148, MRSP 8470 and MRSP 8471 belong to ST919, MRSP
8151 to ST920, MRSP 8473 to ST921 and MRSP 8474 to ST922.

To determine the clonal relationship between the STs detected in this study with those found in the global Pub-MLST S. pseudintermedius database, all the entries available on June 2018 were clustered using the same goeBURST procedure (Fig. 4). The clonal complex (CC) consisted of allelic profiles with five or more allele matches, while singletons were unrelated to any other within the collection. The goeBURST algorithm showed that three of them (STs 919, 920 and 922) are single locus variant with each other, two (STs 649 and 921) are singletons and ST339 is part of a branch located very far from the other isolates. As shown in Fig. 4, none of the isolates in Argentina were related to ST68 or ST71. This data clearly indicates that the MRSP strains are not identical to ST68 and ST71 but evolutionary related.

\section{Comparative genomics and phylogenetic analyses}

Analysis of the MRSP genomes in PATRIC showed an average size of $2,344.838 \mathrm{Mb}$ (range 2.550.634 to 2.650.119), with an average 2779 genes annotated (range 2528 to 2647). The genome composition of MRSP was found similar between the different genomes analyzed (Table 4). A phylogenetic tree that included 152 S. pseudintermedius previously sequenced genomes and the 10 strains in this study was generated (data not shown). Nineteen strains from the representative clades in this tree were selected for a new tree that included the 10 genomes (Table 5 and Fig. 5). The phylogenetic analysis shows that the 10 genomes in this study were not monophyletic, with MRSP 8472 and MRSP 8473 separated from the other eight isolates (Fig. 5) that clustered together.

\section{Discussion}

S. pseudintermedius is a canine and feline commensal and opportunistic pathogen, analogous to $S$. aureus in

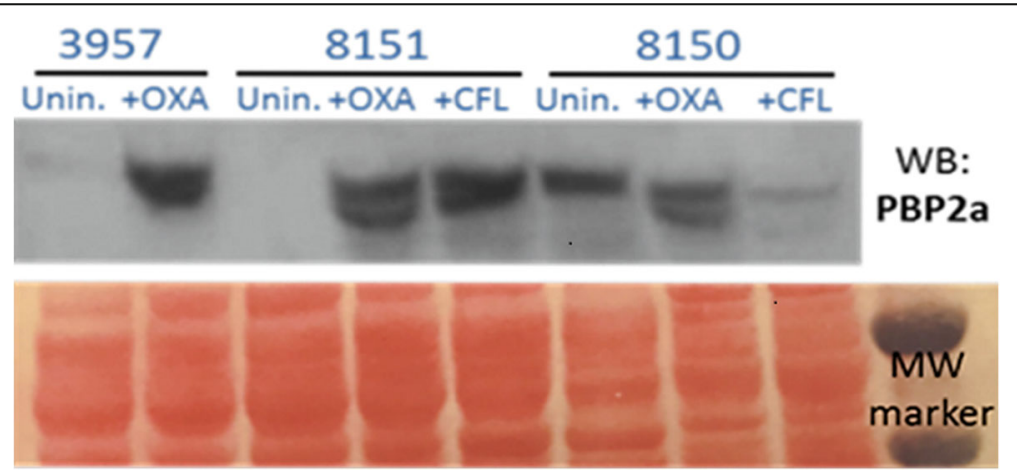

Fig. 1 Western blot analysis of PBP2a protein in lysates of MRSP strains grown without and with subinhibitory concentrations of oxacillin (OXA) and cephalexin (CFL) at $0.5 \mu \mathrm{g} / \mathrm{ml}$. Lower image correspond to Ponceau staining used as loading control. Oxacillin (OXA), cephalexin (CFL), uninduced (Unin) 


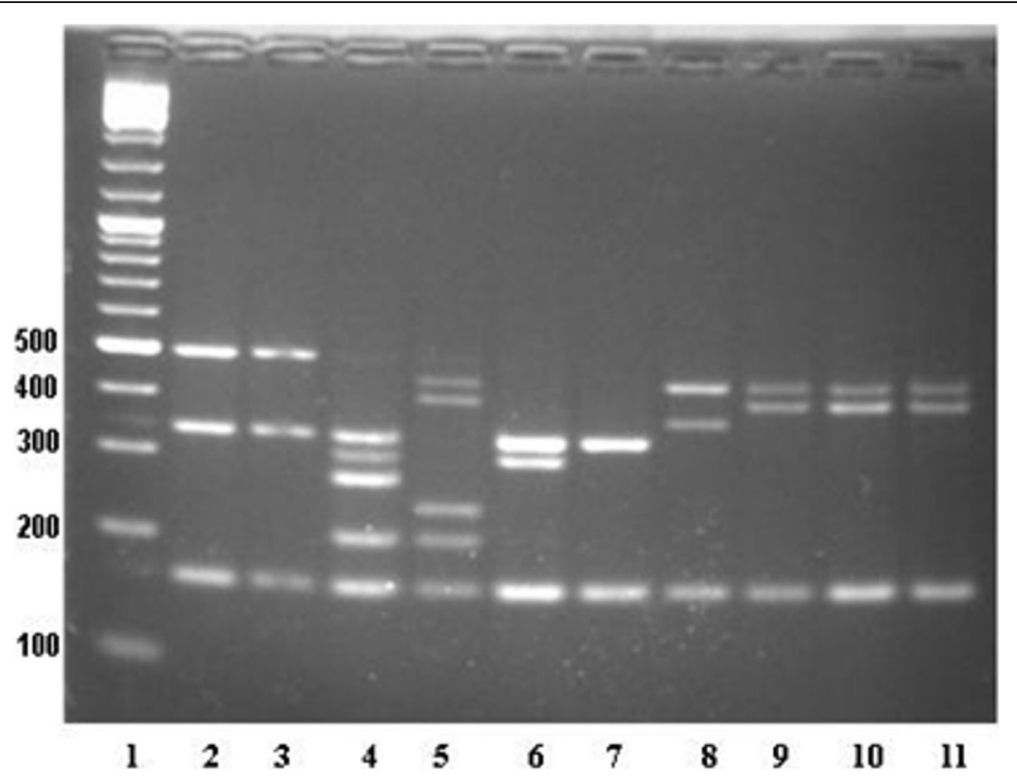

Fig. 2 SCCmec characterization of the MRSP strains by multiplex PCR. Lane 1: MW marker 100 bp; lane 2: SCCmec I; lane 3: SCCmec IA; lane 4: SCCmec II; lane 5: SCCmec III; lane 6: SCCmec IV; lane 7: SCCmec VI; lane 8: SCCmec V; lane 9: MRSP 8148; lane 10: MRSP 8150; lane 11: MRSP 8151

humans. MRSP has recently emerged in small animals worldwide and represents a serious threat to animal health due to its characteristic multidrug resistance phenotype [15].

In this study we compared the resistance phenotype presented by ten clinical strains of MRSP with the genotypic analysis including WGS data. The cefoxitin disk test, which has been shown in several studies to be the most reliable predictor of the presence of $m e c A$ in both S. aureus and coagulase-negative Staphylococcus, does not identify MRSP isolates of human and veterinary origins $[9,10,16]$ and would therefore not have been appropriate for the isolates in this study. Although all the isolates included in the present study were resistant to oxacillin using the current CLSI breakpoints, they could be separated into two groups, with either high or low oxacillin MICs resistance levels. Western blot analyses of PBP2a included the strains MRSP 8150 and MRSP 8151. MRSP 8150 demonstrated a high level of resistance, which was consistent with constitutive membrane levels of PBP2. The levels of PBP2a in MRSP 8151 were only inducible after exposure to oxacillin or cephalexin. The differential expression of $\beta$-lactam resistance has been observed in MRSA [17]. In previous studies,

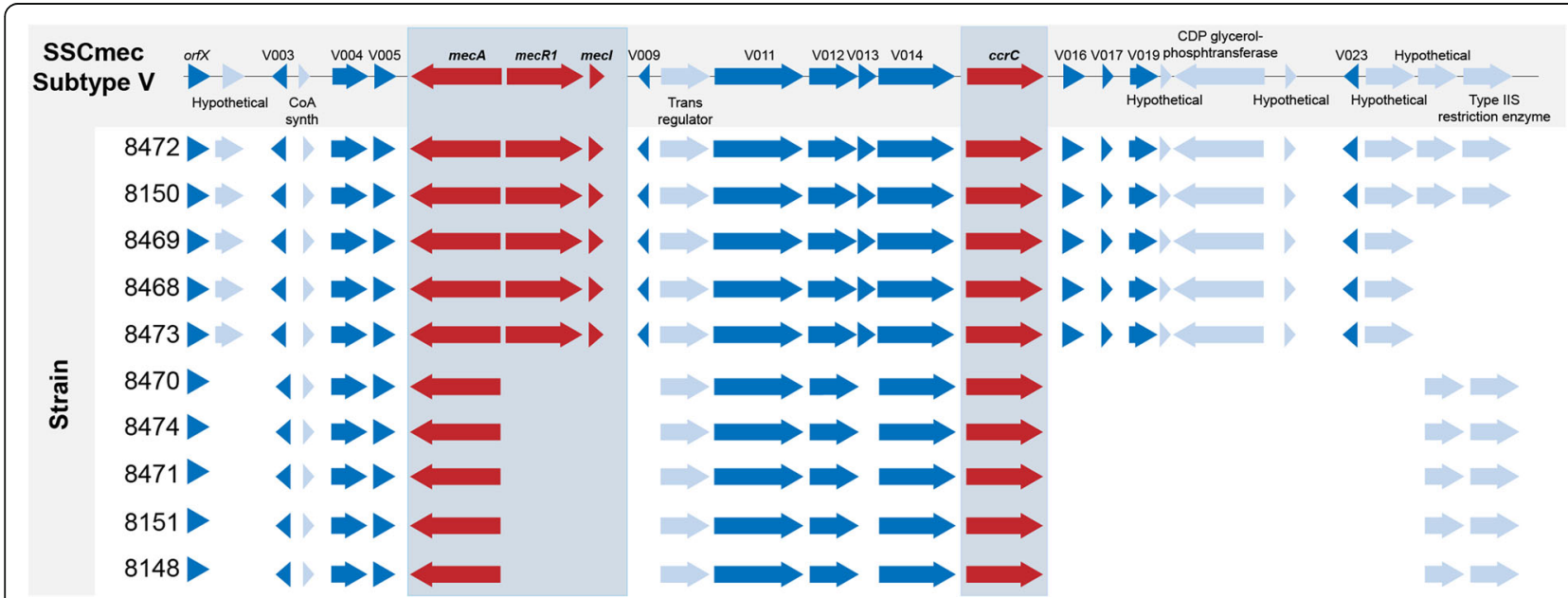

Fig. 3 Comparison of the SCCmec region of the S. aureus TSGH17 (SCCmec V) with the ten isolates of our study. Five of the genomes showed high homology with the SCCmec $V$ compared to the reference genome (TSGH17). The other five genomes have similar ccr complex and mecA and ccrC genes, but were missing many of the other genes associated with SCCmec V, including mecRl and med 


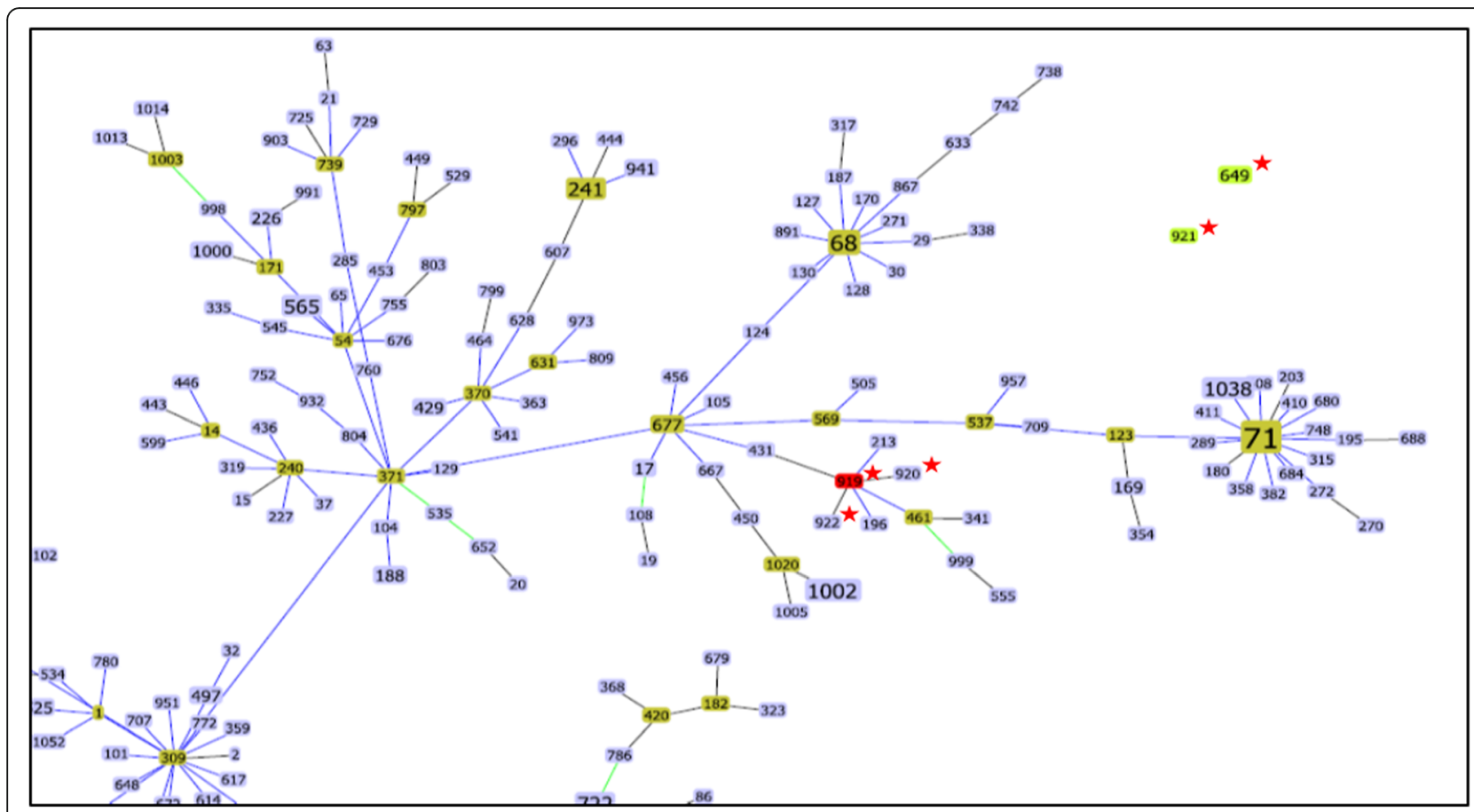

Fig. 4 Population snapshot of MRSP. goeBURST analysis in which the branches are connected with a single locus variant level to show the relation of STs. Stars indicate STs from Argentina. ST339 is not shown in the figure

we have demonstrated that PBP2a can be co-regulated by both mecI and blaI regulators [17]. The observation that blaI/blaR1 regulatory system, present in all the MRSP strains in this study (Table 3 ), led us to speculate that blaI/blaR1 is indispensable to mediate mecA regulation in MRSP. In accordance with this observation, constitutive levels of PBP2a seen in MRSP 8150 may be due to defective function of blaI/blaR1 despite the presence of mecR1/mecI, however this hypothesis awaits experimental confirmation and further studies are needed to demonstrate this finding.

In addition to resistance to $\beta$-lactams, MRSP isolates showed resistance to other antibiotics such as aminoglycosides, macrolides, lincosamides, tetracyclines, trimethoprim/ sulfamethoxazole and fluoroquinolones. Based on these results, all the MRSP that showed resistance to five or six families of antibiotics, were categorized as MDR.

The genes responsible for the resistance to penicillin, tetracycline, erythromycin and trimethoprim/sulfamethoxazole (blaZ, tet $M$, ermB and $d f r G$ genes, respectively) have also been found to be the predominating genes encoding for resistance in S. pseudintermedius from dogs in other studies $[18,19]$. Resistance to aminoglycosides was associated with the adenyl nucleotidyltransferase gene ant(6)-Ia and the phosphotransferase gene aph(3')-III. The bifunctional acetyltransferase/phosphotransferase gene $a a c\left(6^{\prime}\right)-I e-a p h\left(2^{\prime}\right)-I a$ was present only in one gentamicin resistant strain. Comparable results

Table 4 Genomic characteristics of the 10 MRSP strains

\begin{tabular}{llllll}
\hline Strain & Genome ID & Contigs & Genome length (bp) & GC content (\%) & CDS number \\
\hline MRSP 8148 & 283.734 .711 & 1 & $2,617,399$ & 37.54 & 2528 \\
MRSP 8150 & 283.734 .761 & 153 & $2,650,119$ & 37.21 & 2647 \\
MRSP 8151 & 283.734 .762 & 171 & $2,609,428$ & 37.36 & 2630 \\
MRSP 8468 & 283.734 .763 & 126 & $2,584,184$ & 37.32 & 2533 \\
MRSP 8469 & 283.734 .764 & 129 & $2,584,234$ & 37.33 & 2540 \\
MRSP 8470 & 283.734 .765 & 142 & $2,564,903$ & 37.42 & 2537 \\
MRSP 8471 & 283.734 .766 & 142 & $2,550,634$ & 37.24 & 2544 \\
MRSP 8472 & 283.734 .767 & 165 & $2,604,960$ & 37.27 & 2604 \\
MRSP 8473 & 283.734 .768 & 164 & $2,612,019$ & 37.41 & 2598 \\
MRSP 8474 & 283.734 .769 & 168 & $2,621,592$ & & 2636 \\
\hline
\end{tabular}


Table 5 Genomes used for phylogenetic analysis in addition to the new isolates from this study

\begin{tabular}{|c|c|c|c|c|}
\hline Strain & GenBank Accession & Genome Length (bp) & Contigs & Country \\
\hline E140 & ANOI01000000 & 2769458 & 1 & Denmark \\
\hline ED99 & СР002478 & 984892 & 1 & United Kingdom \\
\hline HKU10-03 & СР002439 & 2617381 & 1 & Hong Kong \\
\hline 063228 & СР015626 & 2766566 & 1 & United States \\
\hline 2080722072011 & PEOJ01000000 & 2571729 & 101 & Netherlands \\
\hline 2121129020011 & PEPR01000000 & 2576622 & 63 & Netherlands \\
\hline 2121224012011 & PEPS01000000 & 2650237 & 98 & Netherlands \\
\hline 2130123015011 & PEPV01000000 & 2624816 & 61 & Netherlands \\
\hline 2131211036011 & PEQD01000000 & 2720206 & 100 & Netherlands \\
\hline 41-096 & MPKZ01000000 & 2530792 & 31 & United States \\
\hline MRSP 651 & PHIB01000000 & 2695563 & 37 & United States \\
\hline MRSP 742 & PHHY01000000 & 2637262 & 38 & United States \\
\hline MRSP 424 & PRDQ01000000 & 2660157 & 43 & United States \\
\hline MRSP 980 & PRDR01000000 & 2634738 & 45 & United States \\
\hline NA45 & СР016072 & 2841212 & 1 & United States \\
\hline SL/114 & MQND01000000 & 2590176 & 51 & Sri Lanka \\
\hline SP79 & AP019372 & 2509706 & 1 & Japan \\
\hline ST496 1 & QEJK01000000 & 2746304 & 226 & Australia \\
\hline ST64 2 & QEJT01000000 & 2617379 & 347 & Australia \\
\hline
\end{tabular}

were found in a similar study performed in a veterinary medical teaching hospital in Texas, where the most common aminoglycoside resistance gene found was aph $\left(3^{\prime}\right)$-IIIa, followed by $a a c\left(6^{\prime}\right) / a p h\left(2^{\prime \prime}\right)$ and $\operatorname{ant}\left(4^{\prime}\right)-I a$ genes [20]. Most of the resistance genes detected in $S$. pseudintermedius have also been identified in other species of staphylococci. Only the seven isolates phenotypically resistant to fluoroquinolones had mutations in topoisomerase II ( $g y r A$ S84 L) and IV (grlA S80I) simultaneously. In a previous study Descloux et al. identified numerous base pair exchanges in the genes $\operatorname{gyr} A$, $\operatorname{gyr} B$, grlA and $g r l B$ of S. pseudintermedius resistant to fluoroquinolones [21]. The same substitutions: S84L and E88G in $g y r A$ as well as S80I and D84N in grlA, were seen in fluorquinolone resistant MRSP isolates from Japan [22] and two others S84 L and S80R in gyrA identified in eight ciprofloxacin-resistant MRSP isolates from Spain [23]. Our results show excellent correlation between the resistance phenotypes and the resistance genes detected, similarly to reported recently by other authors [24].

The information gleaned by full genome sequencing of staphylococcal species allows to determine the diversity of SCCmec elements, the structural organization and the genetic content including genetics variants (e.g. inserts, deletions) [25]. SCCmec of S. pseudintermedius displayed some degree of homology to those of $S$. aureus, but sometimes they are untypeable using $\mathrm{SCCmec}$ typing schemes developed for S. aureus. The homology between SCCmec cassettes of different species is considered as an indication of horizontal gene transfer between isolates. SCCmec V is largely homologous to SCCmec type V (5C2\&5), previously named VI or VII from $S$. aureus. Conversely, SCCmec II-III consists in a combination of SCCmec II from S. epidermidis and of SCCmec III from S. aureus and has lacked the cadmium resistance operon, and SCCmec VII-241 is a newly described element that is not related to SCCmec VII from S. aureus [26]. The SCCmec type III variants were found in a study carried out in a veterinary hospital from Japan, where SCCmec type II-III represented $85.2 \%$ of S. pseudintermedius isolates [27]. In our study, according to the multiplex PCR method designed by Milheirico et al for S. aureus, all the isolates appear to be a variant of SCCmec V. SCCmecFinder [14] could only classify five genomes as SCCmec type $\mathrm{V}(5 \mathrm{C} 2 \& 5) / \mathrm{SCC} m e$ c type $\mathrm{Vb}(5 \mathrm{C} 2 \& 5)$ due to the fragmented assemblies of the new isolates. A more detailed analysis of the genomes allowed us to observe that these five genomes not only have $m e c A, m e c R 1$ and mecI, but also have a majority of the genes that are present in the isolate used as reference of SCCmec V. Moreover, two of these genomes had all of the genes present in the S. aureus TSGH17 that was used as a reference. The other five isolates have $\operatorname{mec} A$, but were missing many of the other genes associated with SCCmec V, including mecR1 and mecI. Further studies 


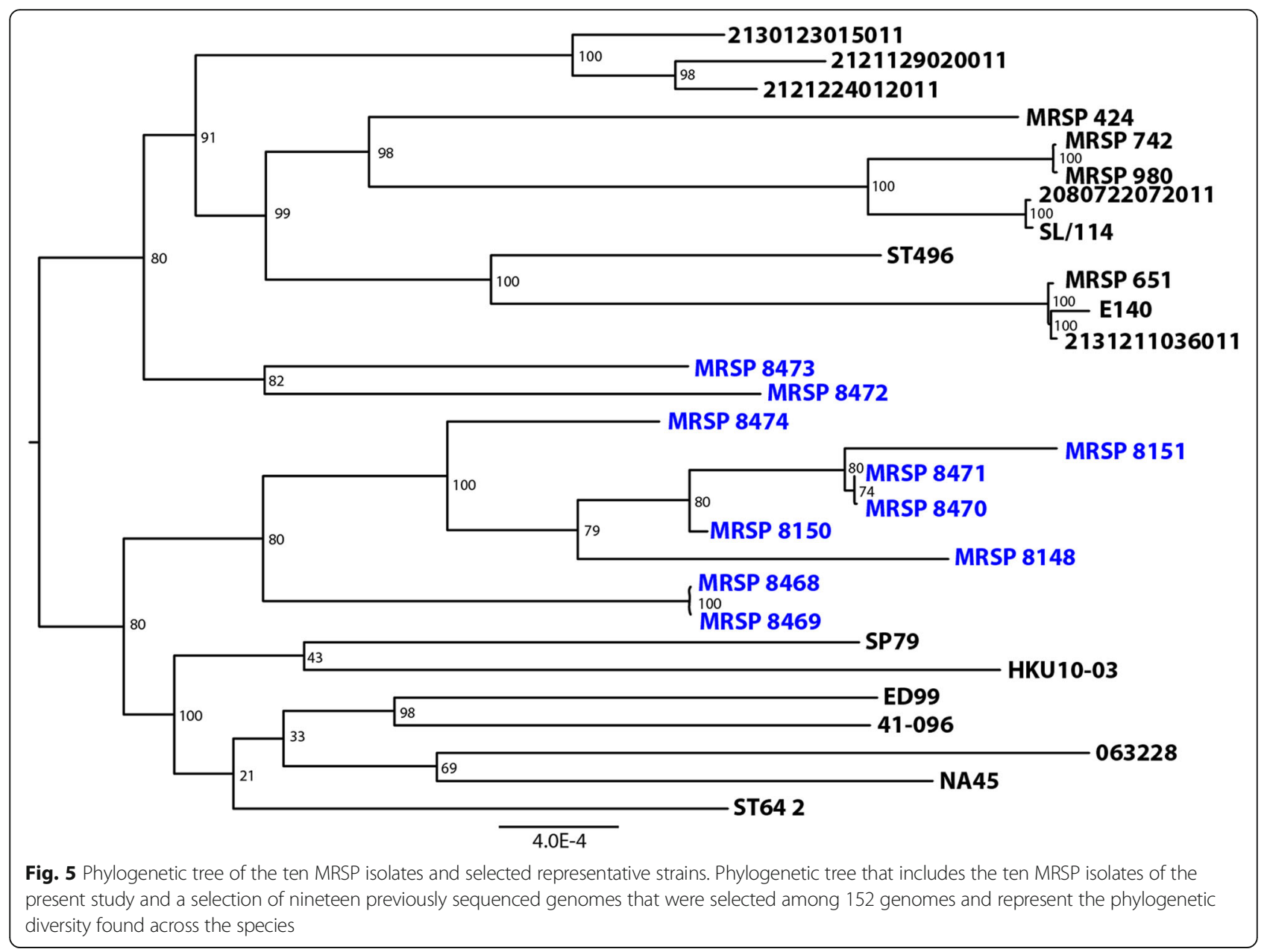

are warranted to characterize the SCCmec element displayed by these isolates, which have the same $c c r C$ recombinase but appears to be a different combination of genes than those described up to now. Although we observed differences in the SCCmec elements between the isolates, the differences in oxacillin MICs seem not to be associated to different $\mathrm{SCCmec}$ types, as has been recently described $[8,28]$.

The dissemination of MRSP isolates tended to be associated with a limited number of clones, unlike methicillin susceptible S. pseudintermedius isolates that presented great genetic diversity [29], similarly to the situation observed in human $S$. aureus. ST68 clone SCCmec V and ST71 SCCmec II-III are the dominant clones that have spread in North America since 2003-04 and in Europe since 2005-06, respectively, but now have a global distribution [30]. A study performed in Brazil was the first in South America to have detected the European clone ST71 of MRSP colonizing companion animals [31]. The isolates of our collection showed significant genetic variation between the population manifested by eight clonal types differentiated by PFGE and six sequence types (STs) by MLST (339, 649, 919, 920, 921 and 922), including four new STs that were genetically distinct from the previous STs in other geographic regions. The analysis by goeBURST of our isolates showed that they were not related to ST68 or ST71. However, ST68 and ST919 are double locus variant from ST677, which could indicate that our isolates are evolutionarily closer to ST68 than ST71. Notably the diversity of STs shown by our MRSP isolates indicates high clonal diversity in our country. We found that both internationally reported as well as previously unreported MRSP STs are present in Argentina. Giving that the clones ST919, ST920, ST921 and ST922 had not been previously reported, it is likely that they represent locally evolved clones.

\section{Conclusions}

In summary, this is the first report addressing the phenotypic and genotypic characterization of canine MRSP isolated in Argentina between 2008 and 2011. 
The ability of MRSP to acquire and maintain resistance genes, and its propensity for horizontal transfer of resistance determinants have shown to represent a potential threat on both the veterinary and Public Health settings.

\section{Methods}

\section{Bacterial strains and identification}

Clinical samples were collected from the infected dogs at three different veterinary hospitals in Buenos Aires, Argentina between 2008 and 2011. Three strains (MRSP 8148, MRSP 8150 and MRSP 8151) were the only methicillin resistant detected in a previously studied strain collection of $28 \mathrm{~S}$. pseudintermedius [11]. The other seven strains were recovered in two laboratories from Buenos Aires city during 2011 and fully characterized at the Antimicrobial Division, INEI-ANLIS "Dr. Carlos G. Malbrán", Regional Reference Laboratory on Antimicrobial Resistance, Buenos Aires, Argentina The ten MRSP isolates included in the present study were isolated from infections in different body sites (Table 1). Species identification was performed by conventional biochemical tests and confirmed by mass spectrometry MALDI-TOF (Bruker Daltonics Microflex LT, Billerica MA, USA). The isolates were pheno- and genotypically characterized at the Antimicrobial Division, INEI-ANLIS "Dr. Carlos G. Malbrán”.

\section{Susceptibility testing of MRSP isolates}

S. pseudintermedius strains were tested by disk diffusion to evaluate their antimicrobial susceptibility to the following antibiotics (disk concentration in brackets): oxacillin $(1 \mu \mathrm{g})$, cefoxitin $(30 \mu \mathrm{g})$, penicillin (10 units), erythromycin $(15 \mu \mathrm{g})$, clindamycin $(2 \mu \mathrm{g})$, tetracycline $(30 \mu \mathrm{g})$, chloramphenicol $(30 \mu \mathrm{g})$, rifampicin $(5 \mu \mathrm{g})$, gentamicin $(10 \mu \mathrm{g})$, streptomycin $(10 \mu \mathrm{g})$, kanamycin $(30 \mu \mathrm{g})$, trimethoprim-sulfamethoxazole $(1.25 / 23.75 \mu \mathrm{g})$, nitrofurantoin $(300 \mu \mathrm{g})$, linezolid $(30 \mu \mathrm{g})$ and ciprofloxacin $(5 \mu \mathrm{g})$. Oxacillin MIC was determined by agar dilution in $\mathrm{MH}$ agar $+2 \% \mathrm{NaCl}$ (CLSI) with a range of antibiotic concentrations from 0.03 to $8 \mathrm{mg} / \mathrm{L}$, and by Etest (bioMérieux, France). All antimicrobial susceptibility tests were carried out according to the CLSI guidelines $[32,33]$. S. pseudintermedius strains were categorized as susceptible, intermediate, or resistant, when the applicable breakpoint was available in CLSI documents VET01S-3rd ed., 2015 or M100S-27th ed., 2017. Despite the lack of CLSI-approved interpretative criteria for streptomycin and kanamycin, the isolates for which the inhibition zone was $6 \mathrm{~mm}$ were considered as resistant. Isolates were considered as multidrug-resistant when they exhibited resistance to three or more different classes of antimicrobial agents [13].

\section{PBP2a analysis in MRSP strains}

Western blot analysis was used to determine changes in PBP2a levels as previously described [34]. Briefly, membrane proteins $(15 \mu \mathrm{g})$ will be extracted from MRSP strains growing with/without sub-inhibitory concentrations of oxacillin and cephalexin (CFL) at $0.5 \mu \mathrm{g} / \mathrm{ml}$ in MHB until mid-exponential phase; cell pellets were resuspended in $600 \mu \mathrm{l}$ of phosphate-buffered saline (PBS), disrupted by adding glass beads and using a FastPrep cell disrupter (MP Biomedicals, Santa Ana, CA, USA); the lysate was centrifuged at $8,000 \times \mathrm{g}$ for $10 \mathrm{~min}$ at $4{ }^{\circ} \mathrm{C}$. The supernatant fraction was centrifuged for an additional 5 min at $8,000 \times \mathrm{g}$ at $4{ }^{\circ} \mathrm{C}$ to remove the beads, and the supernatant transferred to ultracentrifuge tubes and ultracentrifuged at $45,000 \mathrm{rpm}$ for $1 \mathrm{~h} / 4^{\circ} \mathrm{C}$. The membrane pellet was resuspended in PBS, total membrane proteins quantified and stored at $-80{ }^{\circ} \mathrm{C}$. Lysates were separated on 4 to $12 \%$ bis-Tris gels, blot transferred onto pure nitrocellulose blotting membranes, and after blocking (5\% low-fat milk in PBS), PBP2a was probed with monoclonal anti-PBP2a antibody (Slidex MRSA detection kit; bioMérieux, France).

\section{Genotyping}

mecA gene PCR

All the MRSP strains were tested for the presence of the $m e c A$ gene by PCR. PCRs were performed as previously described [35], S. aureus ATCC 43300 and S. aureus ATCC 29213 were used as positive and negative control, respectively.

\section{Identification of SCCmec elements among MRSP strains}

MRSP isolates were first screened for typical SCCmec elements by multiplex PCR as previously described [36]. $S$. aureus collection strains were used as control of each SSCmec type: COL, PER34, BK2464, USA100, ANS46, HU25, USA400, a clinical strain and HDE288 were used as positive control of SCCmec types I, IA, II, III, IV, V and VI respectively [36]. The genome sequence from each of the 10 new isolates was examined in the SSCmecFinder resource [14] to determine the SSCmec type. In addition, the SSCmec V (GenBank Id AY894416) [37] nucleotide and individual protein sequences were compared by BLAST [38] to the new genomes in PATRIC [39]. A careful examination of the region containing the $\mathrm{SCCmec} \mathrm{V}$ genes and its flanking regions was conducted using the Proteome Comparison and Compare Region View [40] tools found in PATRIC. A broad examination for the presence or absence of the protein families that contain mecA, mecR1 and mecI genes across all S. pseudintermedius genomes was conducted using PATRIC's Protein Family Sorter [41].

As the MRSP 8472 genome had all the genes in the SSCmec element present on a single contig, the reads 
from the remaining nine genomes were mapped to that genome using PATRIC's variation service to confirm the presence or absence of the genes in the SCCmec V region. Genes were considered present when reads were present that overlapped both the $5^{\prime}$ and $3^{\prime}$ ends of the genes in MRSP 8472, as well as covering more than $60 \%$ of the total length of the gene.

\section{Pulsed-field gel electrophoresis (PFGE) analysis}

Chromosomal DNA of the MRSP strains digested with Smal was analyzed by PFGE, as described previously [42]. PFGE was carried out by clamped homogeneous electric field electrophoresis with a CHEF DR III System (Bio-Rad Laboratories, Richmond, CA, USA). PFGE was performed under the following conditions: switch time, 2.0 to $20.0 \mathrm{~s}$ and run time, $20 \mathrm{~h}$; temperature $11.3^{\circ} \mathrm{C}$, angle $120^{\circ}$ and voltage $6 \mathrm{~V} / \mathrm{cm}$. Separated DNA fragments were stained with ethidium bromide and visualized with a UV transilluminator. Banding patterns were evaluated by visual inspection and interpreted according to Tenover criteria [43]. Isolates were considered unrelated when the PFGE patterns differed in seven or more bands, consistent with three or more independent genetic events.

\section{Genome sequencing}

Genomic DNA was extracted by using DNeasy Blood and Tissue Kit (QIAGEN, Valencia, CA, USA) as per manufacturer's instructions; concentration was measured by QubitTM assay (Invitrogen, Carlsbad, CA, USA). Illumina library preparation was carried out by Nextera XT DNA Library Preparation Kit (Illumina, San Diego, CA, USA). Hi-seq sequencing was carried out in our affiliated Weill Cornell University (New York, NY, USA) institution at the Epigenetics and Genomic Laboratory, using an Illumina HiSeq 2000. Assembly, annotation and analysis of genomes were done through the PATRIC software (https://www.patricbrc.org). The detection of resistance genes was carried out with PATRIC using the available ResFinder (genomicepidemilogy.org) and CARD (Comprehensive Antimicrobial Resistance Database, card.macmaster.ca) databases, the gene content were compared with the phenotype presented by them.

\section{Population structure analysis}

Sequence types were determined using MLST software (https://bio.tools/mlst). Sequence types were assigned by comparison with the allele sequences present in the PubMLST database (http://pubmlst.org/spseudintermedius) and isolates with a novel combination of alleles were submitted to the MLST database curator Vincent Perreten (vincent.perreten@vetsuisse.vbi.unibe.ch). We determine the clonal relationships of the sequence types obtained in this study with entries in the global
PubMLST S. pseudintermedius database. All entries available at the time of analysis were clustered using the same goeBURST procedure database (http://www.phyloviz.net/goeburst/).

\section{Phylogenetic trees}

An initial tree including $152 \mathrm{~S}$. pseudintermedius genomes, including the 10 isolates sequenced in this study, was created to select appropriate genomes to represent the phylogenetic diversity found across the species. Genomes were selected based on clusters identified in this tree, and as a result, nineteen previously sequenced genomes representing these branches were selected to be compared with the 10 Argentinian genomes.

Protein families from genes that were present as a single copy per genome were selected, and 1000 of these Global protein families (PGFams) [44] were used. Both the protein (amino acid) and gene (nucleotide) sequences were used for each of the selected genes. Protein sequences were aligned using MUSCLE [45], and the nucleotide coding gene for each was aligned using the Codon_align function of BioPython [46]. A concatenated alignment of all proteins and nucloetides were written to a phylip formatted file, and then a partitions file for RaxML [47] was generated, describing the alignment in terms of the proteins and then the first, second and third codon positions. Support values were generated using 100 rounds of the "Rapid" bootstrapping option [48] of RaxML. The resulting newick file was viewed in FigTree [49].

\section{Additional file}

Additional file 1: Figure S1. PFGE of 10 MRSP strains digested with Smal. Lane 1: MW marker; lane 2: MRSP 8148; lane 3: MRSP 8150; lane 4 MRSP 8151; lane 5: MRSP 8468; lane 6: MRSP 8469; lane 7: MRSP 8470; lane 8: MRSP 8471; lane 9: MRSP 8472; lane 10: MRSP 8473; lane 11: MRSP 8474. (TIF $463 \mathrm{~kb}$ )

\section{Abbreviations \\ CC: Clonal complex; CFL: Cephalexin; CLSI: Clinical and Laboratory Standards Institute; IWG-SCC: International Working Group on the Staphylococcal Cassette Chromosome; MDR: Multidrug-resistant; MHB: Mueller-Hinton broth; MIC: Minimal inhibitory concentration; MLST: Multilocus-sequence typing; MRSA: Methicillin-resistant S. aureus; MRSP: Methicillin-resistant S. pseudintermedius; PBP: Penicillin-binding protein; PFGE: Pulsed-field gel electrophoresis; QRDR: Quinolone resistance-determining region; SCCmec: Staphylococcal cassette chromosome; SIG: S. intermedius group; ST: Sequence type; WGS: Whole-genome sequencing; WHO: World Health Organization}

\section{Acknowledgements}

We acknowledge the Epigenomics Core Facility at Weill Cornell Medicine (New York, NY, United States) for their resources and assistance with whole genome sequencing experiments. We thank to Ms. Anna Brock and Dr. Roberto Rosato for contributing to the critical reading and editing of the manuscript. 


\section{Authors' contributions}

The authors have contributed as follows: PG and AER conceived the study and planned the experiments. GG, AD and EB processed the samples and performed laboratory phenotypic analyses. ARW performed the DNA sequence analysis, PG, AC and AER analyzed and interpreted data. PG AER, ARW wrote the manuscript. AC and AER critically revised the manuscript. All authors read and approved the final manuscript.

\section{Funding}

This work was supported by the regular federal budget of the Ministry of Health of Argentina and NIH-R56 Al118756 grant to AER. The sponsors of this study have not being involved in the study design, collection, analysis, data interpretation writing of the manuscript, or in the decision to submit the article for publication.

\section{Availability of data and materials}

The datasets used and/or analysed during the current study are available from the corresponding author on reasonable request.

\section{Ethics approval and consent to participate}

This study was conducted with MRSP strains that were referred to our laboratory with the purpose of identifying their mechanisms of resistance. We did not have any involvement in the samples collection, handling and treatment. For the previous clinical purposes, the samples were collected in accordance with the guidelines for the care and use of animals of the veterinary hospitals of Argentina and informed consent was obtained from dogs owners.

\section{Consent for publication}

Not applicable.

\section{Competing interests}

The authors declare that they have no competing interests.

\section{Author details}

"Servicio Antimicrobianos INEI-ANLIS "Dr. Carlos G. Malbran", CABA, Argentina. ${ }^{2}$ Biocomplexity Institute, University of Virginia, Virginia, USA. ${ }^{3}$ Departamento de Microbiologia, Facultad de Ciencias Veterinarias-UNLP, La Plata, Argentina. ${ }^{4}$ Departamento Microbiología, Instituto de Investigaciones Médicas Alfredo Lanari-UBA, CABA, Argentina. ${ }^{5}$ Department of Pathology and Genomic Medicine, Houston Methodist Research Institute, Houston, TX, USA.

Received: 21 December 2018 Accepted: 2 July 2019

Published online: 27 July 2019

\section{References}

1. Duim B, Verstappen KM, Broens EM, Laarhoven LM, van Duijkeren E, Hordijk J, et al. Changes in the population of methicillin-resistant Staphylococcus pseudintermedius and dissemination of antimicrobial-resistant phenotypes in the Netherlands. J Clin Microbiol. 2016;54:283-8. https://doi.org/10.1128/ JCM.01288-15.

2. Gronthal T, Eklund M, Thomson K, Piiparinen $H$, Sironen $T$, Rantala M. Antimicrobial resistance in Staphylococcus pseudintermedius and the molecular epidemiology of methicillin-resistant $S$. pseudintermedius in small animals in Finland. J Antimicrob Chemother. 2017;72:1021-30. https://doi. org/10.1093/jac/dkw559.

3. Pomba C, Rantala M, Greko C, Baptiste KE, Catry B, van Duijkeren E, et al. Public health risk of antimicrobial resistance transfer from companion animals. J Antimicrob Chemother. 2016;72:957-68. https://doi.org/10.1093/ $\mathrm{jac} / \mathrm{dkw} 481$

4. Miragaia M. Factors contributing to the evolution of mecA-mediated $\beta$ lactam resistance in staphylococci: update and new insights from whole genome sequencing (WGS). Front Microbiol. 2018;9:2723. https://doi.org/1 0.3389/fmicb.2018.02723.

5. International Working Group on the classification of Staphylococcal Cassette Chromosome Elements (IWG-SCC). Classification of staphylococcal cassette chromosome mec (SCCmec): guidelines for reporting novel SCCmec elements. Antimicrob Agents Chemother. 2009;53:4961-7. https://doi.org/1 0.1128/AAC.00579-09.

6. Liu J, Chen D, Peters BM, Li L, Li B, Xu Z, et al. Staphylococcal chromosomal cassettes mec (SCCmec): a mobile genetic element in methicillin-resistant
Staphylococcus aureus. Microb Pathog. 2016;101:56-67. https://doi.org/10.1 016/.micpath.2016.10.028.

7. Shore AC, Deasy EC, Slickers P, Brennan G, O'Connell B, Monecke S, et al. Detection of staphylococcal cassette chromosome mec type XI carrying highly divergent mecA, med, mecR1, blaZ, and ccr genes in human clinical isolates of clonal complex 130 methicillin-resistant Staphylococcus aureus. Antimicrob Agents Chemother. 2011;55:3765-73. https://doi.org/10.1128/ AAC.00187-11.

8. Worthing KA, Schwendener S, Perreten V, Saputra S, Coombs GW, Pang S, et al. Characterization of staphylococcal cassette chromosome mec elements from methicillin-resistant Staphylococcus pseudintermedius infections in Australian animals. mSphere. 2018;3:e00491-18. https://doi. org/10.1128/mSphere.00491-18.

9. Bemis DA, Jones RD, Frank LA, Kania SA. Evaluation of susceptibility test breakpoints used to predict mecA-mediated resistance in Staphylococcus isolated from dogs. J Vet Diagn Investig. 2009;21:53-8. https://doi.org/10.11 77/104063870902100108.

10. Bemis DA, Jones RD, Videla R, Kania SA. Evaluation of cefoxitin disk diffusion breakpoint for detection of methicillin resistance in Staphylococcus pseudintermedius isolates from dogs. J Vet Diagn Investig. 2012;24:964-7. https://doi.org/10.1177/1040638712452112.

11. Vigo GB, Giacoboni Gl, Gagetti PS, Pasteran FG, Corso AC. Antimicrobial resistance and molecular epidemiology of Staphylococcus pseudintermedius strains isolated from dog clinical samples. Rev Argent Microbiol. 2015;47: 206-11. https://doi.org/10.1016/j.ram.2015.06.002.

12. Giacoboni GI, Vinocur F, Fauret N, Grandinetti J, Manzuc P. Detection of Staphylococcus pseudintermedius resistant to methicillin and to other antimicrobials commonly used in canine pyodermias. Analecta Vet. 2017;37: 19-24. https://doi.org/10.24215/15142590e012

13. Magiorakos AP, Srinivasan A, Carey RB, Carmeli Y, Falagas ME, Giske CG, et al. Multidrug-resistant, extensively drug-resistant and pandrug-resistant bacteria: an international expert proposal for interim standard definitions for acquired resistance. Clin Microbiol Infect. 2012;18:268-81. https:/doi.org/1 0.1111/j.1469-0691.2011.03570.x.

14. Kaya H, Hasman H, Larsen J, Stegger M, Johannesen TB, Allesøe RL, et al. SCCmecFinder, a web-based tool for typing of staphylococcal cassette chromosome mec in Staphylococcus aureus using whole-genome sequence data. mSphere. 2018;3:e00612-7. https://doi.org/10.1128/mSphere.00612-17.

15. Paul NC, Moodley A, Ghibaudo G, Guardabassi L. Carriage of methicillinresistant Staphylococcus pseudintermedius in small animal veterinarians: indirect evidence of zoonotic transmission. Zoonoses Public Health. 2011;58: 533-9. https://doi.org/10.1111/j.1863-2378.2011.01398.x.

16. Wu MT, Burnham CA, Westblade LF, Dien Bard J, Lawhon SD, Wallace MA et al. Evaluation of oxacillin and cefoxitin disk and MIC breakpoints for prediction of methicillin resistance in human and veterinary isolates of Staphylococcus intermedius group. J Clin Microbiol. 2016;54:535-42. https:// doi.org/10.1128/JCM.02864-15.

17. Rosato AE, Kreiswirth BN, Craig WA, Eisner W, Climo MW, Archer GL. mecA-blaZ corepressors in clinical Staphylococcus aureus isolates. Antimicrob Agents Chemother. 2003;47:1460-3. https://doi.org/10.1128/AAC.47.4.1460-1463.2003.

18. Kadlec K, Schwarz S. Antimicrobial resistance of Staphylococcus pseudintermedius. Vet Dermatol. 2012;23:276-82. https://doi.org/10.1111/ j.1365-3164.2012.01056.x.

19. Norstrom M, Sunde M, Tharaldsen H, Mørk T, Bergsjø B, Kruse H. Antimicrobial resistance in Staphylococcus pseudintermedius in the Norwegian dog population. Microb Drug Resist. 2009;15:55-9. https://doi.org/10.1089/mdr.2009.0865.

20. Gold RM, Cohen ND, Lawhon SD. Amikacin resistance in Staphylococcus pseudintermedius isolated from dogs. J Clin Microbiol. 2014;52:3641-6. https://doi.org/10.1128/JCM.01253-14.

21. Descloux S, Rossano A, Perreten V. Characterization of new staphylococcal cassette chromosome mec (SCCmec) and topoisomerase genes in fluoroquinolone- and methicillin-resistant Staphylococcus pseudintermedius. I Clin Microbiol. 2008;46:1818-23. https://doi.org/10.1128/JCM.02255-07.

22. Onuma K, Tanabe T, Sato H. Antimicrobial resistance of Staphylococcus pseudintermedius isolates from healthy dogs and dogs affected with pyoderma in Japan. Vet Dermatol. 2012;23:17-22. https://doi.org/10.1111/ j.1365-3164.2011.00995.x.

23. Gomez-Sanz E, Torres C, Lozano C, Sáenz Y, Zarazaga M. Detection and characterization of methicillin-resistant Staphylococcus pseudintermedius in healthy dogs in La Rioja, Spain. Immunol Microbiol Infect Dis. 2011;34:44753. https://doi.org/10.1016/j.cimid.2011.08.002. 
24. Wegener A, Broens EM, Zomer A, Spaninks M, Wagenaar JA, Duim B. Comparative genomics of phenotypic antimicrobial resistances in methicillin-resistant Staphylococcus pseudintermedius of canine origin. Vet Microbiol. 2018;225:125-31. https://doi.org/10.1016/j.vetmic.2018.09.013.

25. Perreten V, Chanchaithong P, Prapasarakul N, Rossano A, Blum SE, Elad D, et al. Novel pseudo-staphylococcal cassette chromosome mec element ( $4 S C C$ mec57395) in methicillin-resistant Staphylococcus pseudintermedius CC45. Antimicrob Agents Chemother. 2013;57:5509-15. https://doi.org/1 0.1128/AAC.00738-13.

26. Perreten V, Kadlec K, Schwarz S, Gronlund Andersson U, Finn M, Greko C, et al. Clonal spread of methicillin-resistant Staphylococcus pseudintermedius in Europe and North America: an international multicentre study. J Antimicrob Chemother. 2010;65:1145-54. https://doi.org/10.1093/jac/dkq078.

27. Ishihara K, Shimokubo N, Sakagami A, Ueno H, Muramatsu Y, Kadosawa T, et al. Occurrence and molecular characteristics of methicillin-resistant Staphylococcus aureus and methicillin-resistant Staphylococcus in academic veterinary hospital. Apppl Environ Microbiol. 2010;25:5165-74. https://doi. org/10.1128/AEM.02780-09.

28. Kasai T, Saegusa S, Shirai M, Murakami M, Kato Y. New categories designated as healthcare-associated and community-associated methicillinresistant Staphylococcus pseudintermedius in dogs. Microbiol Immunol. 2016; 60:540-51. https://doi.org/10.1111/1348-0421.12401.

29. Pires dos Santos T, Damborg P, Moodley A, Guardabassi L. Systematic review on global epidemiology of methicillin-resistant Staphylococcus pseudintermedius: inference of population structure from multilocus sequence typing data. Front Microbiol. 2016;7:1599. https://doi.org/10.3389/fmicb.2016.01599.

30. McCarthy AJ, Harrison EM, Stanczak-Mrozek K, Leggett B, Waller A, Holmes $M A$, et al. Genomic insights into the rapid emergence and evolution of MDR in Staphylococcus pseudintermedius. J Antimicrob Chemother. 2015;70: 997-1007. https://doi.org/10.1093/jac/dku496.

31. Quitoco IM, Ramundo MS, Silva-Carvalho MC, Souza RR, Beltrame CO, de Oliveira TF, et al. First report in South America of companion animal colonization by the USA1100 clone of community-acquired meticillinresistant Staphylococcus aureus (ST30) and by the European clone of methicillin-resistant Staphylococcus pseudintermedius (ST71). BMC Res Notes. 2013;6:336. https://doi.org/10.1186/1756-0500-6-336.

32. Clinical and Laboratory Standards Institute (CLSI). VET01-S 3rd Edition. Performance standards for antimicrobial disk and dilution susceptibility tests for bacteria isolated from animals. Wayne, PA, USA; 2015.

33. Clinical Laboratory Standards Institute (CLSI). M100S 27th Edition: performance standards for antimicrobial susceptibility testing. Clinical Laboratory Standards Institute, Wayne, PA, USA. 2017.

34. Fernandez R, Paz LI, Rosato RR, Rosato AE. Ceftaroline is active against heteroresistant methicillin-resistant Staphylococcus aureus clinical strains despite associated mutational mechanisms and intermediate levels of resistance. Antimicrob Agents Chemother. 2014;58:5736-46. https://doi. org/10.1128/AAC.03019-14

35. Vannuffel P, Gigi J, Ezzedine H, Vandercam B, Delmee M, Wauters G, et al. Specific detection of methicillin-resistant Staphylococcus species by multiplex PCR. J Clin Microbiol. 1995;33:2864-7 PMCID: PMC228596 PMID: 8576335.

36. Milheirico C, Oliveira DC, de Lencastre H. Update to the multiplex PCR strategy for assignment of mec element types in Staphylococcus aureus. Antimicrob Agents Chemother. 2007;51:3374-7. https://doi.org/10.1128/ AAC.00275-07.

37. Boyle-Vavra S, Ereshefsky B, Wang CC, Daum RS. Successful multiresistant community-associated methicillin-resistant Staphylococcus aureus lineage from Taipei, Taiwan, that carries either the novel staphylococcal chromosome cassette mec (SCCmec) type VT or SCCmec type IV. J Clin Microbiol. 2005;43:4719-30. https://doi.org/10.1128/JCM.43.9.4719-4730.2005.

38. Altschul SF. BLAST algorithm. 2001.

39. Wattam AR, Davis JJ, Assaf R, Boisvert S, Brettin T, Bun C, et al. Improvements to PATRIC, the all-bacterial bioinformatics database and analysis resource center. Nucleic Acids Res. 2016;45(D1):D535-42. https://doi.org/10.1093/nar/gkw1017.

40. Overbeek R, Olson R, Pusch GD, Olsen GJ, Davis JJ, Disz T, et al. The SEED and the rapid annotation of microbial genomes using subsystems technology (RAST). Nucleic Acids Res. 2013:42(D1):D206-14. https://doi.org/10.1093/nar/ gkt1226.

41. Wattam AR, Gabbard JL, Shukla M, Sobral BW. Comparative genomic analysis at the PATRIC, a bioinformatic resource center, in Host-Bacteria Interactions Methods. Mol Biol. 2014;1197:287-308. https://doi.org/10.1007/ 978-1-4939-1261-2_17.
42. Chung $M$, de Lencastre $H$, Matthews $P$, Tomasz $A$. The multilaboratory project collaborators. Molecular typing of methicillin resistant Staphylococcus aureus (MRSA) by pulsed field gel electrophoresis: comparison of results obtained in a multilaboratory effort using identical protocols and MRSA strains. Microb Drug Resis. 2000;6:189-98. https://doi.org/10.1089/mdr.2000.6.189.

43. Tenover FC, Arbeit RD, Goering RV, Mickelsen PA, Murray BE, Persing DH, et al. Interpreting chromosomal DNA restriction patterns produced by pulsed-field gel electrophoresis: criteria for bacterial strain typing. J Clin Microbiol. 1995:33:2233-9 PMCID: PMC228385 PMID: 7494007.

44. Davis JJ, Gerdes S, Olsen GJ, Olson R, Pusch GD, Shukla M, et al. PATtyFams: protein families for the microbial genomes in the PATRIC database. Front Microbiol. 2016;7:118. https://doi.org/10.3389/fmicb.2016.00118.

45. Edgar RC. MUSCLE: multiple sequence alignment with high accuracy and high throughput. Nucleic Acids Res. 2004;32:1792-7. https://doi.org/10.1093/ nar/gkh340.

46. Cock PJ, Antao T, Chang JT, Chapman BA, Cox CJ, Dalke A, et al. Biopython: freely available Python tools for computational molecular biology and bioinformatics. Bioinformatics. 2009;25:1422-3. https://doi.org/10.1093/ bioinformatics/btp163.

47. Stamatakis A. RAxML version 8: a tool for phylogenetic analysis and postanalysis of large phylogenies. Bioinformatics. 2014;30:1312-3. https://doi. org/10.1093/bioinformatics/btu033.

48. Stamatakis AP, Hoover P, Rougemont J. A rapid bootstrap algorithm for the RAxML web servers. Syst Biol. 2008;57:758-71. https://doi.org/10.1080/1 0635150802429642.

49. Rambaut A. FigTree, a graphical viewer of phylogenetic trees. 2007.

\section{Publisher's Note}

Springer Nature remains neutral with regard to jurisdictional claims in published maps and institutional affiliations.

\section{Ready to submit your research? Choose BMC and benefit from:}

- fast, convenient online submission

- thorough peer review by experienced researchers in your field

- rapid publication on acceptance

- support for research data, including large and complex data types

- gold Open Access which fosters wider collaboration and increased citations

- maximum visibility for your research: over $100 \mathrm{M}$ website views per year

At BMC, research is always in progress.

Learn more biomedcentral.com/submissions 